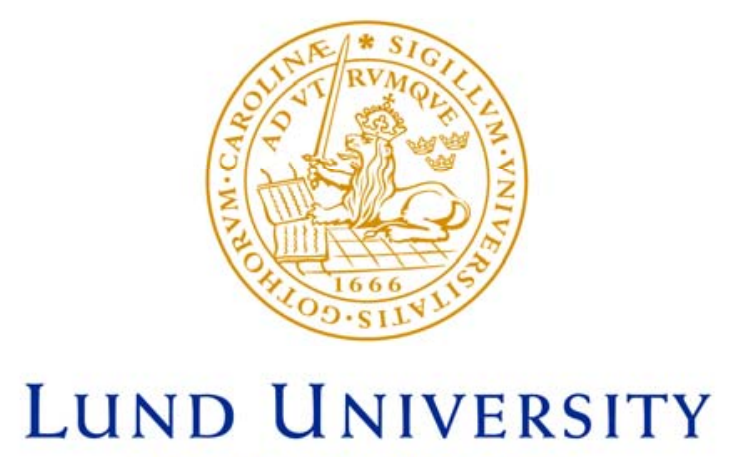

Faculty of Medicine

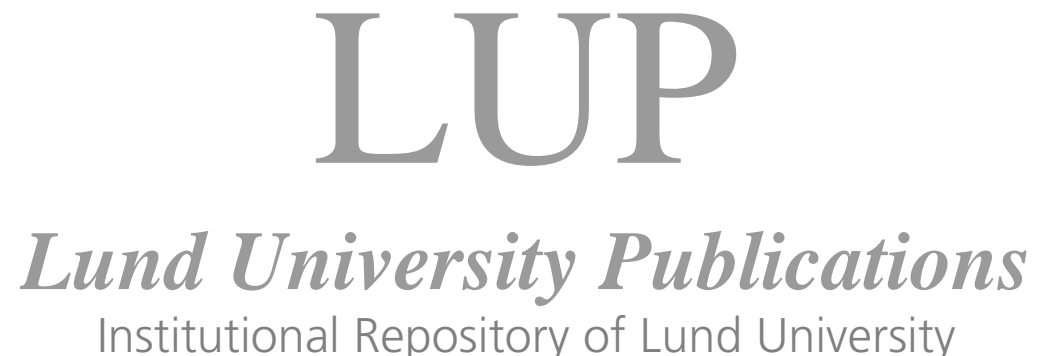

Institutional Repository of Lund University

This is an author produced version of a paper published in

The Journal of laryngology and otology. This paper has been peer-reviewed but does not include the final publisher proof-corrections or journal pagination.

Citation for the published paper:

K J Brännström, J Grenner

"Hypobaric pressure exposure effects on cochlear frequency selectivity in fluctuating, low-frequency hearing loss."

The Journal of laryngology and otology, 2009, Issue: Jan 12, p 1-8

http://dx.doi.org/10.1017/S0022215109004228

Access to the published version may require journal subscription.

Published with permission from:

Cambridge University Press 


\section{Hypobaric pressure exposure effects on cochlear frequency selectivity in fluctuating low-frequency hearing loss.}

K. Jonas BRÄNNSTRÖM, MSc in Audiology

Department of Clinical Science, Lund University

Section of Audiology, ENT-department, Malmö University Hospital, Sweden

Jan GRENNER, MD., Ph.D

Department of Clinical Science, Lund University.

Section of Audiology, ENT-department, Lund University Hospital, Sweden

Corresponding author: ～K. Jonas Brännström

Address: $\quad$ Department of Audiology

SE-205 02 MALMÖ

Phone: $\quad$ +46(0)702830056

E-mail: _ jonas.brannstrom@med.lu.se

The results have been previously presented at the $2^{\text {nd }}$ joint meeting between the Acoustical Society of America and the European Acoustical Association, Acoustics '08, in Paris, France, 29/6-4/7 2008. 


\section{Abstract}

Aim: To study the effects of hypobaric pressure chamber exposure on cochlear frequency selectivity in subjects with monaural fluctuating low-frequency hearing loss, such as Ménière’s disease.

Methods: We used a hypobaric pressure chamber to create relative underpressure in the ear canal to impose positive pressure gradients to the inner ear. Psychophysical tuning curves (PTC), transiently evoked otoacoustic emissions (TEOAE) and speech recognition scores in noise was measured in 10 subjects with fluctuating low-frequency hearing loss before and after pressure exposure.

Results: After the exposure, overall pure tone average showed no improvement, but individual results showed improved SPEECH RECOGNITION SCORES in noise (six subjects), increased TEOAE strength (three subjects) and increased steepness for PTCs (two subjects). Deteriorations were also seen, mainly in PTCs. No association could be established between the different tests and measured parameters could not predict subjective improvement. Conclusion: The results suggest variable effects of hypobaric pressure exposure on inner ear physiology.

\section{Keywords}

Frequency selectivity

Psychophysical tuning curves

Hypobaric pressure chamber

Otoacoustic emissions

Speech recognition

Ménière’s disease

Endolymphatic hydrops 


\section{Introduction}

In the present report, we study the effect of hypobaric pressure exposure on cochlear frequency selectivity measured as psychophysical tuning curves (PTC), transiently evoked otoacoustic emissions (TEOAE) and speech recognition scores in subjects with monaural fluctuating low-frequency hearing loss and monaural Ménière’s disease. Ménière’s disease is closely related to increased inner ear pressure (fluid volume), i.e. endolymphatic hydrops ${ }^{1,2}$ and is usually associated with fluctuating low-frequency hearing loss. Studies on the effect of pressure on cochlear physiology in subjects with Ménière's disease have been made using the relative overpressure in the middle ear obtained after exposure in hypobaric pressure chambers to impose pressure gradients to the inner ear ${ }^{3-6}$. These studies have aimed to assess possible effects on the inner ear regarding primary hearing thresholds, speech recognition scores and in some cases otoacoustic emissions (i.e. outer hair cell function). Hearing improvements have been observed among some subjects ${ }^{3-7}$. Increases in speech recognition scores have been observed after pressure exposure ${ }^{3,8}$, a finding also observed by the authors during a pilot study. It is known that cochlear frequency selectivity affects speech recognition scores ${ }^{9}$.

Increased inner ear pressure in endolymphatic hydrops is believed to mostly affect passive mechanics of the apical partition of the inner ear membranes, which increases the travelling wave velocity, and to shift the characteristic place of basilar membrane displacement towards the base of the cochlea ${ }^{10-16}$. In Ménière’s disease and other fluctuating low-frequency hearing loss of cochlear origin, the relocation of travelling wave displacement might be manifested as off-frequency listening (i.e. low frequency tones are detected by high frequency hair cells) ${ }^{17-}$ 20; off-frequency listening may be observed through PTCs. 
The aim of the present report was to study the effect of hypobaric pressure exposure on cochlear frequency selectivity measured as PTC, TEOAE and speech recognition scores in noise in subjects with Ménière’s disease and monaural, fluctuating, low-frequency hearing loss.

\section{Materials and methods}

\section{Subjects}

Ten subjects (4 women and 6 men, mean age 59 years SD \pm 13 ) diagnosed with monaural fluctuating low-frequency hearing loss participated in the study. All subjects showed normal otological status in both ears and no previous history of middle ear diseases. Descriptive data are presented in Table I including baseline low-frequency and high-frequency pure tone hearing thresholds, given as pure tone averages (PTAs). (Lower frequency PTAs were measured at three frequencies in the range $0.125-0.5 \mathrm{kHz}$ and high frequency PTAs at three frequencies in the range 1.0-4.0 kHz.) Subjects are presented in monotonically increasing exposure duration. Six of the subjects were diagnosed with Ménière’s disease; the diagnosis Ménière's disease was made in accordance with the guidelines of the American Academy of Otolaryngology-Head and Neck Surgery’s Committee on Hearing and Equilibrium Guidelines

${ }^{21}$. Four subjects that had no vertiginous experience at all were classified as having fluctuating low-frequency hearing loss without vertigo using the same criterions (vertigo excluded). The cochlear origin of the fluctuating low-frequency hearing loss had been confirmed prior to inclusion through otomicroscopy, pure tone audiometry, speech audiometry, impedance audiometry and auditory brainstem response audiometry and in some cases also through magnetic resonance imaging (MRI). 
All tests - tympanometry, speech recognition scores in noise, TEOAE, Békésy-audiometry, and PTCs - were conducted by or under supervision by the first author in a sound-proof booth at about ten meters above sea level with its’ prevailing (i.e. normal ambient) atmospheric pressure. These tests were made both before and after pressure exposure. Less than 15 minutes elapsed between the conclusion of the pre-exposure test session and the beginning of the pressure exposure. In the same manner, less than 15 minutes elapsed between the conclusion of the pressure exposures and the initiation of the post-exposure test session. Written and oral instructions were given before each test. Written instructions were also given on a computer screen during the PTC-test. The subjects were also given opportunity to ask questions about the tests and procedures used. The total time consumption for all tests and the pressure exposures were approximately 270 minutes. Investigations were performed in accordance with the Helsinki Declaration and the Ethics Committee of Lund University approved the study (LU 509-03).

\section{Tympanometry, speech recognition scores in noise and otoacoustic emissions}

Initially, before pressure exposure, normal otological status was verified and tympanometry was conducted using either a GSI 33 middle-ear analyser or a GSI Tympstar middle-ear analyser (GSI, Madison, MI, United States) $(0.226 \mathrm{kHz}$ probe tone and pressure range -300 to $200 \mathrm{daPa}$ ). Speech recognition scores in noise was performed according to Magnusson ${ }^{22}$; fifty phonemically balanced monosyllabic words at the end of carrier sentence were presented through TDH-39P earphones (Telephonics, Interacoustics, Assens, Denmark) using an Orbiter 922 audiometer (Madsen Electronics, GN Otometrics, Taastrup, Denmark), calibrated in a 6 cc-coupler according to the reference sound pressure levels stated in ISO 389-1 ${ }^{23}$. Wordlists were randomly assigned. TEOAE measurements were performed using default set-up in the non-linear mode using either an ILO88 Otodynamics otoacoustic emission analyser (software 
version 5.60Y) or an ILOv6 Otodynamics otoacoustic emission analyser (stimulus level range 83 to 85 dB peak equivalent (p.e.) SPL) (Otodynamics Ltd., Hetfield, United Kingdom). The noise rejection level used was $\leq 51 \mathrm{~dB}$ p.e. SPL and the noise input level range was between 34 and 45 dB p.e. SPL.

\section{Békésy audiometry}

A PC with an external sound card (M-Audio Audiophile (24 bits/48 kHz); M-Audio, Ohringen, Germany), and sound shielded circumaural Sennheiser HDA 200 earphones (Sennheiser, Tullamore, Ireland) were used. Custom-built computer program (designed with Matlab 6.5 software) was used for generation and presentation of the stimuli and it also recorded the subject's responses (for more details, please refer to Brännström \& Grenner ${ }^{24)}$. The stimuli generation and the equipment calibration was made in accordance to ISO 389-8 ${ }^{25}$. The stimuli and the complete set-up were calibrated according to IEC 60318-1 ${ }^{26}$ and 60318-2 ${ }^{27}$ using a Brüel and Kjaer 2231 sound level meter with a 4134 microphone in a 4153 coupler (Brüel and Kjaer, Naerum, Denmark). The stimuli used were pulsed pure tones for the octave frequencies $0.125 \mathrm{kHz}$ to $8 \mathrm{kHz}$. The pure tones were gated on during $240 \mathrm{~ms}$ including 20 ms rise and fall times with a $160 \mathrm{~ms}$ silent interval between presentations. Seventy-five presentations were used per frequency. The rate of the intensity change was 2.5 $\mathrm{dB}$ per second. The arithmetic mean of all reversals of the individual frequencies was used to calculate the hearing threshold at each frequency. A fast Fourier transform (FFT) made on the acoustical output showed a total harmonic distortion for the complete system that was less than $1 \%$. 
The same equipment, set-up and calibration as for the Békésy-audiometry were used in the recordings of PTC. This method has also been previously described in detail in Brännström \& Grenner ${ }^{24,28}$. PTCs were measured for using two $0.25 \mathrm{kHz}$ probe tones presented at $10 \mathrm{~dB}$ SL (sensation level) during simultaneous narrowband noise presentation. These two probe tones were separated by $500 \mathrm{~ms}$ of silence and the length of each tone was $500 \mathrm{~ms}$ long including 20 ms rise and fall times. The duration of the narrowband noises used were 3500 ms including $20 \mathrm{~ms}$ rise and fall times. A single run consisted of the simultaneous presentation of a narrowband noise and the two probe tones. Each run was followed by a $2400 \mathrm{~ms}$ silent interval before next run. Seven narrowband noises were used and the centre frequencies of the filters used to obtain these noises were $0.24,0.43,0.78,0.92,1.0,1.08$ and 1.23 times the probe tones $(0.25 \mathrm{kHz})^{29}$. The width of the filters used was $20 \%$ or a maximum of $320 \mathrm{~Hz}$ of the centre frequency of the filter ${ }^{29}$. These stimuli were generated using Matlab 6.5 software. The slopes of each narrowband masker were verified by FFT of the acoustical output and were found to be steeper than $28 \mathrm{~dB}$ /octave. A “6 dB up and $3 \mathrm{~dB}$ down”-procedure (two threshold passages) regulated the intensity of narrowband noise presentations. The subjects indicated by pressing a button if they detected both probe tones during the noise presentation.

\section{Hypobaric pressure chamber}

The pressure chamber used is located at the ENT-department at Malmö University Hospital, Sweden, at the same elevation as the test booth used for the audiological tests. It has previously been used in studies by e.g. Konrádsson et al. ${ }^{3,30}$. The subjects were placed in the pressure chamber in an upright sitting position. The middle ear pressure was monitored through a probe (presenting a $0.226 \mathrm{kHz}$ probe tone) placed in the outer ear canal of the affected ear during the whole exposure ${ }^{31-33}$. Initially, the subjects were instructed not to swallow and the pressure in the chamber decreased relatively fast ( $>10 \mathrm{daPa} /$ second) until the 
middle ear pressure exceeded the individual pressure opening level of the Eustachian tube (range among all subjects between 100 to >500 daPa). After this level was established, the following pressure exposures - during which the subjects also were instructed not to swallow - were close to this level, but below, to avoid spontaneous opening of the tube. This level was maintained during five minutes (or until spontaneous opening). The level was normalised again slowly (3-5 daPa/second), the subjects were instructed to swallow after the normalisation and then middle ear pressure was measured again; if the subject's Eustachian tube opened spontaneously, the level was normalised in the same manner. This procedure was repeated 4 to 7 times with a couple of minutes rest at ambient pressure between pressure exposures.

All subjects received an evaluation protocol about 6 weeks after their pressure exposure. This evaluation asked about subjective changes in hearing, tinnitus, aural fullness and vertigo.

\section{Statistical analysis}

Spearman's rank correlation coefficient (rho) was calculated to assess associations between each subject's tests. The paired-sample T test was used to calculate significant differences between before and after pressure exposure. p-values $\leq 0.05$ were considered statistically significant.

\section{Results and analysis}

Tympanometry made after the pressure exposures showed middle ear pressures within normal limits in the affected ear for all subjects (range -30 to 0 daPa). 
The PTA-LF results were improved after pressure exposure in only one subject, subject 7 (degrees of freedom, $\mathrm{DF}=2, \mathrm{p}<0.05$ ), and deteriorated in two subjects, subjects 2 and 3 (DF $=2, \mathrm{p}<0.05$ ) (c.f. Table I). No significant changes were seen in the PTA-HF. There are data missing for subject 1 since the subject chose to quit before PTA could be measured after exposure.

\section{Speech recognition scores in noise}

As seen in Table I, speech recognition scores in noise in the affected ear were improved in six subjects (subjects 3, 5, 6, 7, 8, and 9) unchanged in one (subject 10), and deteriorated in one (subject 2). Subject 4 showed no speech recognition scores in noise both before (2\%) and after the exposure (0\%). Also here, data are missing for subject 1 after pressure exposure due to the same reason as for the PTA. On average, speech recognition scores in noise after pressure exposure were improved, but significantly only in the unaffected ear (before $=74 \%$, after $=67 \%$; $D F=8, p<0.05$ ) and not in the affected ear (before $=38 \%$, after $48 \%$; $D F=8$, $\mathrm{p}=0.09)$.

\section{Otoacoustic emissions}

Individual TEOAE results in the affected ear are presented in Figure 1 as improvements in $\mathrm{dB}$ calculated from the emission strength (dB SPL). There are no data for subject 5 (after pressure exposure) due to database malfunction. Subjects 3 and 6 showed reproducible TEOAEs only for the whole tested frequency range (i.e. mean of buffers A and B) and not for single frequency bands. Significant improvements (indicated with asterisks in Figure 1) were seen for subjects 1, 2, $8(\mathrm{DF}=9, \mathrm{p}<0.01)$, and $4(\mathrm{DF}=5, \mathrm{p}<0.01)$. 


\section{Psychophysical tuning curves}

The individual PTC-results before and after pressure exposure are shown in Figure 2.

Generally, poor frequency selectivity was observed among most subjects both before and after the pressure exposure; $\mathrm{Q}_{10}$, a measure of frequency selectivity, could only be calculated in three cases before and four cases after pressure exposure $\left(\mathrm{Q}_{10}\right.$ was calculated by dividing the probe tone frequency with the bandwidth of the curve $10 \mathrm{~dB}$ above the tip of the tuning

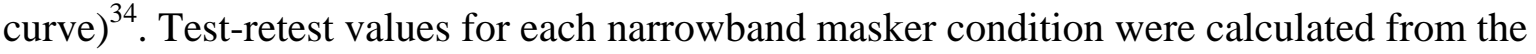
mean results of all ten subjects before and after exposure, according to the method of Arlinger et al. ${ }^{35}$. The test-retest values are presented in Table II and significant deviations outside this interval are marked as asterisks in Figure 2. The individual results in Figure 2 may be classified according to their configurations. First, two subjects showed PTCs after exposures that were changed in relative level but showed no change in shape (subjects 1 and 6). Second, two subjects showed PTCs with improved shape, i.e. higher levels at most narrowband maskers were seen except at the frequency of the probe tone (subjects 2 and 9). Two subjects showed possibly improved PTC shapes (subjects 5 and 7); the results for subject 5 suggested off-frequency listening before exposure and on-frequency listening after, but the similar change seen for subject 7 is minimal. Third, two subjects showed PTCs with deteriorated shape after exposure, i.e. increased masker levels at the frequency of the probe tone deleting a previous (non-dubious) tip of the tuning curve (subject 3) or splitting it in two (subject 4). Finally, two subjects showed some changes in the overall masker levels with possibly deteriorated PTC shapes (subject 8 and 10).

After equalising the sound pressure levels of the maskers of the individual subjects to the level of the probe tone (10 dB SL), the mean results for all subjects indicated slightly, but significantly, improved PTCs after pressure exposure $(\mathrm{DF}=6, \mathrm{p}<0.05)$. Improvement in this 
case means that increased intensities were seen at all masker frequencies except for the masker with the same centre frequency as the probe tone.

\section{Subjective improvement}

The recorded improvements were not associated with the subjective improvement stated in the follow-up questionnaire. This means that the outcome of the measurements could not predict which subject who would subjectively benefit from the pressure exposure.

\section{Discussion}

In the present report, the effects of hypobaric pressure exposure on hearing and frequency selectivity was studied in subjects with monaural fluctuating low-frequency hearing loss, such as Ménière’s disease. The results suggest small, if any, effects on hearing thresholds. The results of the individual subjects suggest improvement, no effect, or deterioration in cochlear frequency selectivity assessed as speech recognition scores in noise, TEOAEs, and PTCs before and after pressure exposure. Subjects showing improvements in one test sometimes show deterioration in another test.

\section{Hypobaric pressure effects on hearing thresholds}

Most subjects showed no change in PTA after the pressure exposure. Only one subject showed significantly improved PTA-LF and two subjects showed significantly deteriorated PTA-LF (no significant changes were seen for PTA-HF). PTA improvements has previously been reported (in about $50 \%$ of the subjects) after different types of pressure exposures (hypobaric pressure chamber or local application of overpressure in the ear canal) in subjects with Ménière’s disease ${ }^{3-5,8,36}$. Konrádsson et al. ${ }^{3}$ also reported increasing PTA improvement 
with increasing maximum relative overpressure in the middle ear obtained during pressure chamber exposure. No such association could be observed in the present study.

Notably, two subjects showed significantly deteriorated PTA-LF after the pressure exposure is conspicuous. It can be suggested that both improvement and deterioration could be the effect of hypobaric pressure chamber exposure on endolymphatic hydrops, since reduction in inner ear fluid volume may affect the mobility of the cochlear membranes differently depending on whether a residual pressure gradient between the cochlear compartments is present or not. Long-standing distension of Reissner’s membrane causing decreased compliance may be the cause of the rise of such a lasting rise in the pressure gradient ${ }^{37}$. However, the matter is further complicated by the fact that distensions and ruptures of Reissner's membrane are known to occur (mostly apically) during endolymphatic hydrops 1,2,38 . Furthermore, in the hydropic ear, the tectorial membrane may be shrivelled and detached from the hair cells after such distension or rupture ${ }^{39,40}$. Both these latter histopathological findings would largely affect hearing sensitivity and frequency selectivity.

\section{Hypobaric pressure effects on frequency selectivity}

A small majority of the subjects showed improvements in speech recognition scores in noise after pressure exposure (subjects 3, 5, 6, 7, and 9). These improvements in speech recognition scores in noise showed no association with any PTA improvements; this could suggest a possible influence of the pressure exposure on hearing not related to hearing thresholds. Changes in inner ear pressure may affect physiology of hearing but it need not result in only hearing threshold improvements. Konrádsson et al. ${ }^{3}$ reported an inverse relationship between PTA and summating potential measured through electrocochleography in subjects with Ménières disease after exposure in hypobaric pressure chamber suggesting possibly separate 
mechanisms contributing differently to hearing physiology. Although the observed differences in the present study were small, it might be suggested that these improved scores indicate the effect of improvements in the frequency selectivity of the inner ear. However, it could also be possible that we observed some kind of learning process resulting in higher scores after pressure exposure, even though wordlists before and after exposure were randomly assigned.

In the present study, the outer hair cell function was assessed by TEOAE. The outer hair cells probably improve the frequency selectivity of the cochlea by their active tuning of the basilar membrane ${ }^{41}$. An increase in TEOAE emission strength after pressure exposure may thus indicate increased outer hair cell motility, possibly affecting frequency selectivity. Improvements in TEOAE emission strength were seen indeed seen in the results after pressure exposure in six subjects (subjects 1, 2, 4, 7, 8, and 9). This improved motility may be explained by previous findings suggesting that pressure exposure, most likely, creates a change in the hydrodynamic properties of cochlea ${ }^{8,42,43}$. Increased fluid transportation probably decreases inner ear pressure (and perhaps also a change in the ionic content of the endolymphatic fluid). One effect of reduced inner ear fluid volume could be increased motility in the basilar membrane and its outer hair cells seen in the present data as increased emission strength after exposure. Improved PTCs could have been explained in a similar manner. However, there is no association between improved PTC-tuning and increased TEOAEs in the present results. Small, but significant, changes were observed in most subjects, but both improvements and deteriorations were seen. The two subjects with improved PTC-shape (subjects 2 and 9) also showed increases in TEOAEs after exposure. However, the overall lack of congruence between TEOAE-results and PTC-results seen here 
is difficult to account for. Further research, possibly on normal hearing subjects, is required to further explore these findings.

\section{Conclusions}

The results in present study suggest that hypobaric pressure chamber exposure may improve, deteriorate, or not affect cochlear frequency selectivity measured as speech recognition scores in noise, TEOAEs, and PTCs in subjects with monaural fluctuating low-frequency hearing loss, such as Ménières disease. The observed effects were generally small and the results are inconclusive. Since improvements in frequency selectivity were not accompanied by improvements in audiometric hearing thresholds, it is suggested that the pure tone audiogram may be a too blunt measure of inner ear physiology when monitoring effects of hypobaric pressure exposure.

\section{Acknowledgements}

Financial support for this research was received from the Hearing Foundation (The Swedish Association of Hard of Hearing People, Sweden), Lund University (grant ALF-05 governmental grant for clinical research), the Stinger Foundation for Audiological Research, and the Swedish Society of Audiologists. The authors would like to thank Ann Reutherborg, who operated the hypobaric pressure chamber. 


\section{References}

1 Kimura RS. Review on histopathology of Ménière’s disease. In: Vesterhauge S, Katholm M, Mikines P, eds. Ménière’s disease. Proceedings of the16th Danavox Symposium, sept. 1922, 1995. Kolding, Denmark: Scanticon, 1995: 93-103

2 Xenellis JE, Linthicum FHJ, Webster P, Lopez R. Basilar membrane displacement related to endolymphatic sac volume. Laryngoscope 2004; 114: 1953-59

3 Konrádsson KS, Carlborg B, Grenner J, Tjernström O. Electrocochleographic and audiometric evaluation of hypobaric effect in Ménière's disease. Laryngoscope 1999; 109: 5964

4 van Deelen GH, Hulk J, Huizing EH. The use of underpressure chamber in the treatment of patients with Meniere's disease. J Laryngol Otol 1987; 101: 229-35

5 Kitahara M, Kodama A, Izukura H, Ozawa H. Effect of atmospheric pressure on hearing in patients with Meniere's disease Acta Otolaryngol Suppl 1994; 510: 111-12

6 Tjernström O, Casselbrant M, Harris S, Ivarsson A. Current status of pressure chamber treatment. Otolaryngol Clin North Am 1980; 13: 723-29

7 Tjernström O. Pressure chamber treatment. In: Pfaltz CR, ed. Controversial aspects of Ménière's disease, 1st edn. Stuttgart: Thieme Verlag, 1986: 96-98 
8 Densert B. Effects of overpressure on hearing function in Meniere's disease. Acta Otolaryngol 1987; 103: 32-42

9 Stelmachowicz PG, Jesteadt W, Gorga MP, Mott J. Speech perception ability and psychophysical tuning curves in hearing impaired listeners. J Acoust Soc Am 1985; 77: 62027

10 Donaldson GS, Ruth RA. Derived band auditory brain-stem response estimates of traveling wave velocity in humans. I: Normal-hearing subjects. J Acoust Soc Am 1993; 93: $940-51$

11 Donaldson GS, Ruth RA. Derived band auditory brain-stem response estimates of traveling wave velocity in humans. II: Subjects with noise-induced hearing loss and Meniere's disease. J Speech Hear Res 1993; 39: 534-45

12 Allen GW. Clinical implications of experiments on alteration of the labyrinthine fluid pressure. Otolaryngol Clin North Am 1983; 16: 3-19

13 Tonndorf J. Endolymphatic hydrops: Mechanical causes of hearing loss. Arch Otorhinolaryngol 1976; 212: 293-99

14 Don M, Kwong B, Tanaka C. A diagnostic test for Ménière's disease and cochlear hydrops: Impaired high-pass noise masking of auditory brainstem responses. Otol Neurotol 2005; 26: 711-22 
15 Thornton AR, Farrell G. Apparent travelling wave velocity changes in cases of endolymphatic hydrops. Scand Audiol 1991; 20: 13-18

16 Serbetcioglu M, Parker D. Measures of cochlear travelling wave delay in humans: I. Comparison of three techniques in subjects with normal hearing. Acta Otolaryngol 1999; 119: $537-43$

17 Huss M, Moore BC. Dead regions and pitch perception. J Acoust Soc Am 2005; 117: $3841-52$

18 Turner C, Burns EM, Nelson DA. Pure tone pitch perception and low-frequency hearing loss. J Acoust Soc Am 1983; 73: 966-75

19 Burns EM, Turner C. Pure-tone pitch anomalies. II. Pitch-intensity effects and diplacusis in impaired ears. J Acoust Soc Am 1986; 79: 1530-40

20 Florentine M, Houtsma AJ. Tuning curves and pitch matches in a listener with a unilateral, low-frequency hearing loss. J Acoust Soc Am 1983; 73: 961-5

21 Committee on hearing and equilibrium guidelines for the diagnosis and evaluation of therapy in Meniere's disease. Otolaryngol Head Neck Surg 1995; 113: 181-85

22 Magnusson L. Reliable clinical determination of speech recognition scores using Swedish PB words in speech-weighted noise. Scand Audiol 1995; 24: 217-23 
23 ISO 389-1. Acoustics: Reference zero for the calibration of audiometric equipment. Part 1: Reference equivalent threshold sound pressure levels for pure tones and supra-aural earphones. International Organization for Standardization 389-1, 1998

24 Brännström J, Grenner J. Clinical application of long-term intensity and pitch matches in fluctuating low-frequency hearing loss. Int J Audiol 2008; 47: 412-19

25 ISO 389-8. Acoustics: Reference zero for the calibration of audiometric equipment. Part 8: Reference equivalent threshold sound pressure levels for pure tones and circumaural earphones. International Organization for Standardization 389-8, 2004

26 IEC 60318-1 I. Electroacoustics - Simulators of human head and ear - Part 1: Ear simulator for the calibration of supra-aural earphones. Geneva: International Electrotechnical Commission, 1998

27 IEC 60318-2 I. Electroacoustics - Simulators of human head and ear - Part 2: An interim acoustic coupler for the calibration of audiometric earphones in the extended high-frequency range. Geneva: International Electrotechnical Commission; 1998

28 Brännström J, Grenner J. Long-term measurement of binaural intensity and pitch matches. II. Fluctuating low-frequency hearing loss. Int J Audiol 2008; 47: 675-687.

29 Moore BC, Alcantara JI. The use of psychophysical tuning curves to explore dead regions in the cochlea. Ear Hear 2001; 22: 268-78 
30 Konrádsson KS, Svensson O, Carlborg B, Grenner J. Tympanic pressure gradients and otoacoustic emissions. Ear Hear 1999; 20: 403-09

31 Carlborg B, Farmer JJ, Carlborg A. Effects of hypobaric pressure on the labyrinth. Cochlear aqueduct patent. Acta Otolaryngol 1990; 110: 386-93

32 Konrádsson KS, Carlborg A, Farmer JJ, Carlborg B. Perilymph pressure during hypobaric conditions - cochlear aqueduct obstructed. Acta Otolaryngol 1994; 114: $24-29$

33 Carlborg B, Konrádsson KS, Carlborg A, Farmer JJ, Densert O. Pressure transfer between the perilymph and the cerebrospinal fluid compartments in cats. Am J Otol 1992; 13: 41-48

34 van den Abeele D, van de Heyning PH, Creten W, Graff AM, JFE. Psychoacoustical tuning curves. Scand Audiol 1992; 21: 3-8

35 Statistical aspects on measurement accuracy. In: Arlinger SD, ed. Manual of practical audiometry, volume 2, 1st edn. London: Whurr Publishers Ltd., 1993: 24-30

36 Larsen HC, Angelborg C. Low-pressure chamber test in Meniere's disease. Acta Otolaryngol Suppl 1991; 481: 474-76

37 Böhmer A. Hydrostatic pressure in the inner ear fluid compartments and its effects on inner ear function. Acta Otolaryngol Suppl 1993; 507: 3-24 
38 Martini A, Prosser S. Disorders of the inner ear in adults. In: Luxon LM, ed. Textbook of audiological medicine. Clinical aspects of hearing and balance, 1st edn. London: Martin Dunitz, 2003: 451-76

39 Schuknecht HF. Pathology of the ear. Cambridge: Harvard University Press, 1974

40 Schuknecht HF, Igarashi M. Pathophysiology of Ménière's disease. In: Pfaltz CR, ed. Controversial aspects of Ménière's disease, 1st edn. Stuttgart: Thieme Verlag, 1986: 46-54

41 Patuzzi R. Cochlear micromechanics and macromechanics. In: Dallos P, Popper AN, Fay RR, eds. The cochlea, 1st edn. New York: Springer-Verlag, 1996: 186-257

42 Ödkvist LM, Arlinger SD, Billermark E, Densert B, Lindholm S, Wallqvist J. Effects of middle ear pressure changes on clinical symptoms in patients with Ménière's disease - a clinical multicentre placebo-controlled study. Acta Otolaryngol Suppl 2000; 543: 99-101

43 Carlborg B, Densert B, Densert O. Functional patency of the cochlear aqueduct. Ann Otol Rhinol Laryngol 1982; 91: 209-15 


\section{Legends}

Table I. Descriptive data for 10 patients with unilateral fluctuating low-frequency hearing loss regarding diagnosis (fluctuating low-frequency hearing loss without vertigo, probable, possible, or definitive Ménière's disease), sex, age, affected ear, pure tone average (PTA-LF) (0.125-0.5 kHz), PTA-HF (1.0-4.0 kHz), speech recognition scores (SRS) in noise (\%) before and after hypobaric pressure chamber exposure and subjective improvements (Yes/No) in the affected ear at follow-up.

Table II. Psychophysical tuning curves test. Significant test-retest difference for each narrowband masker. Data derived from average values for all 10 subjects, before and after hypobaric pressure exposure. "Masker frequency” indicate multiplication factor applied to $0.25 \mathrm{kHz}$ probe tone to derive narrowband masker centre frequency. Test-retest difference $\mathrm{SD} * 1.96 * 1.4$

Figure 1. Change in transient otoacoustic emission (TEOAE) strength after hypobaric pressure exposure, at individual frequency bands (FBs) (one-third of an octave wide) and the 
full frequency range (taken as mean of buffers A and B), or individual subjects. Asterisks denote statistically significant changes $(\mathrm{p}<0.05)$.

Figure 2. Psychophysical tuning curves obtained in the subjects' affected ear before (continuous line, circle plots) and after (broken line, square plots) hypobaric pressure exposure, using narrowband maskers with a centre frequency (CF) of 0.24, 0.43, 0.78, 0.92, $1.00,1.08$ and 1.23 times the $0.25 \mathrm{kHz}$ probe tone. The level of the probe tone was $10 \mathrm{~dB}$ sensation level. * = Statistically significant changes (see Table II); + = probe tone; V = probe tone if adjusted after exposure (only necessary in subjects 3 and 7 ); $\wedge=$ thresholds higher than measurable range (>120 dB SPL); SPL = sound pressure level.

\section{Tables}

Table I.

\begin{tabular}{|c|c|c|c|c|c|c|c|c|c|c|c|c|c|c|}
\hline \multirow[t]{2}{*}{$\begin{array}{c}\text { Subject } \\
\text { no }\end{array}$} & \multirow[t]{2}{*}{ Diagnosis } & \multirow[t]{2}{*}{ Sex } & \multirow[t]{2}{*}{$\begin{array}{l}\text { Age } \\
\text { (y) }\end{array}$} & \multirow[t]{2}{*}{ Ear } & \multirow{2}{*}{$\begin{array}{c}\text { PTA-LF } \\
\text { (dB HL) } \\
\text { pre }\end{array}$} & \multirow[b]{2}{*}{ post } & \multirow{2}{*}{$\begin{array}{c}\text { PTA-HF } \\
\text { (dB HL) } \\
\text { pre } \\
\end{array}$} & \multirow[b]{2}{*}{ post } & \multirow{2}{*}{$\begin{array}{c}\text { SRS } \\
\text { (percent } \\
\text { correct) } \\
\text { pre } \\
\end{array}$} & \multirow[b]{2}{*}{ post } & \multicolumn{3}{|c|}{ Subjective improvement? } & \multirow[b]{2}{*}{$\begin{array}{c}\text { Aural } \\
\text { pressure }\end{array}$} \\
\hline & & & & & & & & & & & Hearing & Vertigo & Tinnitus & \\
\hline 1 & FLFHL & $\mathrm{F}$ & 61 & $\mathrm{~L}$ & 18 & $\mathrm{x}$ & 7 & $\mathrm{x}$ & 80 & $\mathrm{x}$ & $\mathrm{N}$ & $\mathrm{N}$ & $\mathrm{N}$ & $\mathrm{N}$ \\
\hline 2 & Poss MD & M & 58 & $\mathrm{~L}$ & 56 & 57 & 27 & 29 & 38 & 26 & $\mathrm{Y}$ & $\mathrm{N}$ & $\mathrm{Y}$ & $\mathrm{Y}$ \\
\hline 3 & Poss MD & M & 61 & $\mathrm{R}$ & 55 & 66 & 44 & 50 & 10 & 22 & Y & $\mathrm{N}$ & $\mathrm{N}$ & $\mathrm{N}$ \\
\hline 4 & FLFHL & M & 81 & $\mathrm{~L}$ & 45 & 45 & 39 & 37 & 2 & 0 & $\mathrm{~N}$ & $\mathrm{~N}$ & $\mathrm{~N}$ & $\mathrm{~N}$ \\
\hline 5 & Def MD & M & 26 & $\mathrm{R}$ & 42 & 43 & 30 & 29 & 52 & 60 & $\mathrm{~N}$ & $\mathrm{~N}$ & $\mathrm{~N}$ & $\mathrm{~N}$ \\
\hline 6 & Prob MD & $\mathrm{F}$ & 59 & $\mathrm{~L}$ & 18 & 17 & 35 & 33 & 48 & 58 & $\mathrm{~N}$ & $\mathrm{~N}$ & $\mathrm{~N}$ & $\mathrm{~N}$ \\
\hline 7 & FLFHL & F & 61 & $\mathrm{~L}$ & 53 & 49 & 25 & 23 & 42 & 66 & $\mathrm{Y}$ & $\mathrm{N}$ & $\mathrm{N}$ & $\mathrm{Y}$ \\
\hline 8 & FLFHL & $\mathrm{F}$ & 56 & $\mathrm{~L}$ & 37 & 35 & 15 & 8 & 38 & 68 & $\mathrm{~N}$ & $\mathrm{~N}$ & $\mathrm{~N}$ & $\mathrm{~N}$ \\
\hline 9 & Prob MD & M & 56 & $\mathrm{~L}$ & 17 & 18 & 37 & 37 & 46 & 50 & $\mathrm{Y}$ & $\mathrm{N}$ & $\mathrm{Y}$ & $\mathrm{Y}$ \\
\hline 10 & Poss MD & M & 69 & L & 41 & 26 & 22 & 17 & 68 & 68 & $\mathrm{Y}$ & $\mathrm{N}$ & $\mathrm{Y}$ & $\mathrm{N}$ \\
\hline
\end{tabular}


Table II.

\begin{tabular}{cccc}
\hline $\begin{array}{c}\text { Masker } \\
\text { frequency }\end{array}$ & $\begin{array}{c}\text { Masker } \\
\text { Mean }\end{array}$ & $\begin{array}{c}\text { level } \\
\text { SD }\end{array}$ & $\begin{array}{c}\text { Test-retest } \\
\text { Difference (dB) }\end{array}$ \\
\hline & & & \\
0.24 & 37,6 & 1,4 & 3,7 \\
0.43 & 28,1 & 1,0 & 2,7 \\
0.78 & 16,4 & 0,6 & 1,6 \\
0.92 & 8,8 & 0,2 & 0,6 \\
1.0 & 7,0 & 0,2 & 0,6 \\
1.08 & 11,2 & 0,4 & 1,2 \\
1.23 & 15,1 & 0,3 & 0,8 \\
\hline
\end{tabular}

Figure 1.

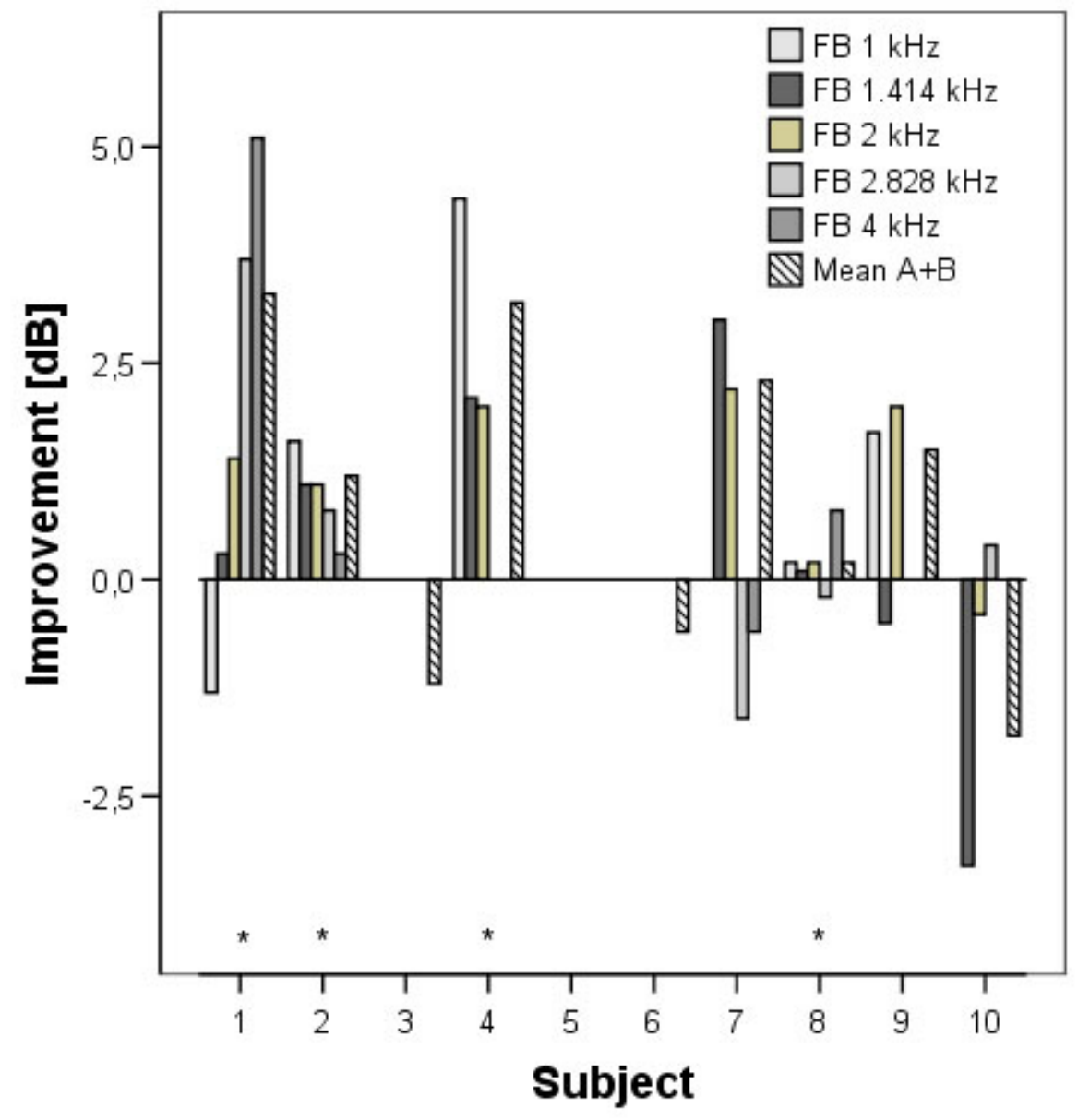


Figure 2. 

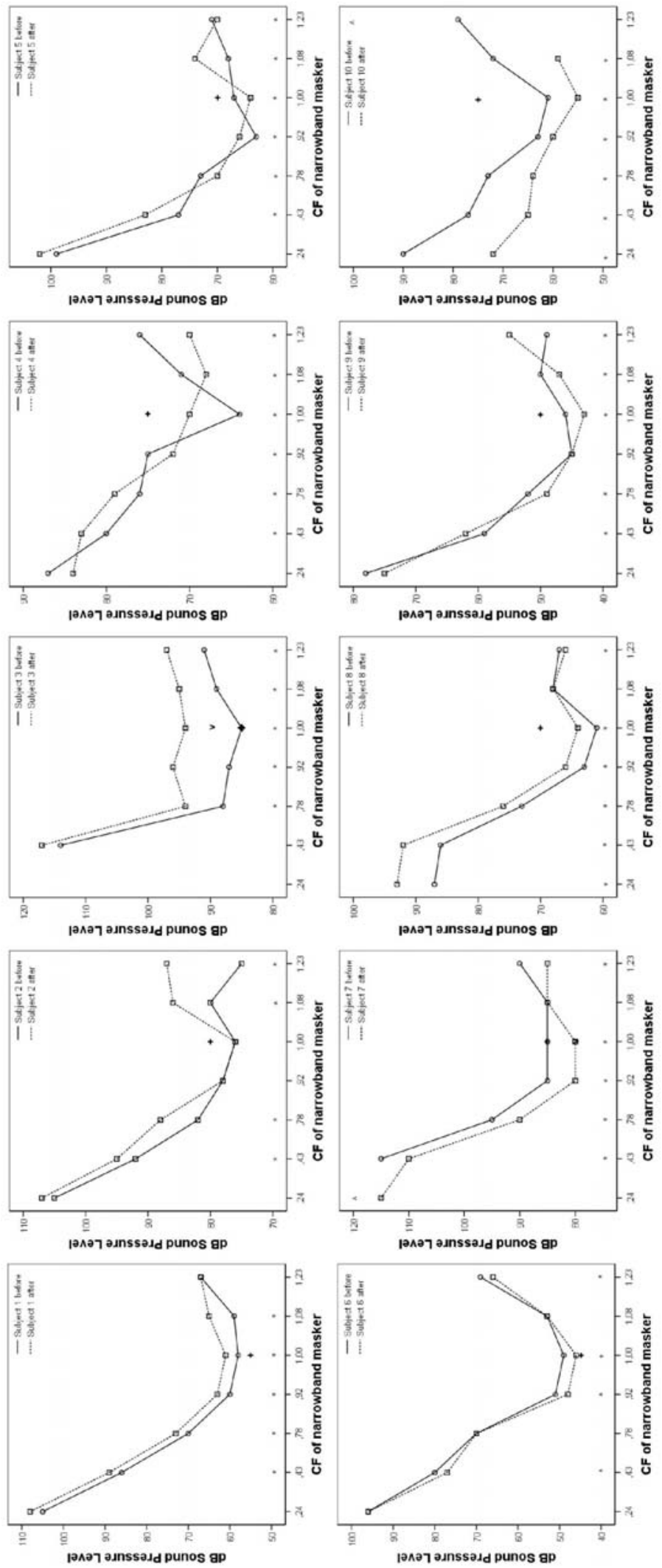